\title{
Lost Incunable Editions: Closing in on an Estimate
}

\author{
Jonathan Green and Frank McIntyre
}

Imagine, if you will, that you are a lepidopterist stationed in the butterfly-rich environment of a tropical Malaysian island. You hope to determine the number of butterfly species that live on the island, and so you resolve to survey an acresized patch of it for a month and record the number of individuals of each species that you find. At the end of the month, you find that a few species of butterfly are represented by a large number of specimens, while many species are represented by only one or a few specimens. These results lead you to suspect that there remain many species of butterfly on the island that your survey has missed, but how many? And how many more species can you expect to discover with additional months of observation? As your opportunity to spend additional months on a tropical island depends on your presenting a convincing argument to your funding agency, these questions are of some urgency for you.

This is a brief statement of what is known as the unseen species problem, which has been an area of intense study both within and well outside of the field of ecology for several decades. The example above concerning Malaysian butterflies is drawn from a pathbreaking article published in 1943 by Ronald Fisher, one of the founders of modern biology and statistics, who proposed statistical methods for estimating the number of unseen butterfly species. ${ }^{1}$ Since then, the development and implementation of these methods has continued, so that several current statistical software packages can provide both an estimate of the number of missing species and determine the confidence interval of that estimation, that is, the range within which one is reasonably certain the actual number lies. ${ }^{2}$ In an ideal situation, the number of observed butterfly species will rise with each additional month of observation, but the estimate of total species will change only modestly as the confidence interval

1 R.A. Fisher, A. Steven Corbet and C.B. Williams, 'The Relation between the Number of Species and the Number of Individuals in a Random Sample of an Animal Population', Journal of Animal Ecology, 12 (1943), pp. 42-58.

2 For a comprehensive overview of research on this question, see J. Bunge and M. Fitzpatrick, 'Estimating the Number of Species: A Review', Journal of the American Statistical Association, 88 (1993), pp. 364-373. Bunge maintains an updated bibliography on the unseen species problem and related problems in statistics at <https://courses.cit.cornell.edu/jab18/bibliography .html>. 
grows narrower and narrower (and, one hopes, the grant to observe butterflies on a tropical island is extended indefinitely). Variations on the unseen species problem have a long history in the humanities, including attempts to determine the total size of Shakespeare's vocabulary or to estimate the number of different dies used for stamping issues of ancient coins. ${ }^{3}$

Mention of dies, stamps, and issues should suggest to scholars of early printing that we have our own variation of the unseen species problem, where copies are the specimens and editions are the species. A formulation of the unseen species problem in print history - in larval form, at least - was advanced by Ernst Consentius already in 1932: "How many incunables are for example present in seven copies, in six copies, etc. down to the vast number of incunables that are only known in one copy. Plotted on a graph, these numbers produce a curve whose course might provide information for the question: What has been lost to us?"4 (See the realization of the graph proposed by Consentius in fig. 3.1.)

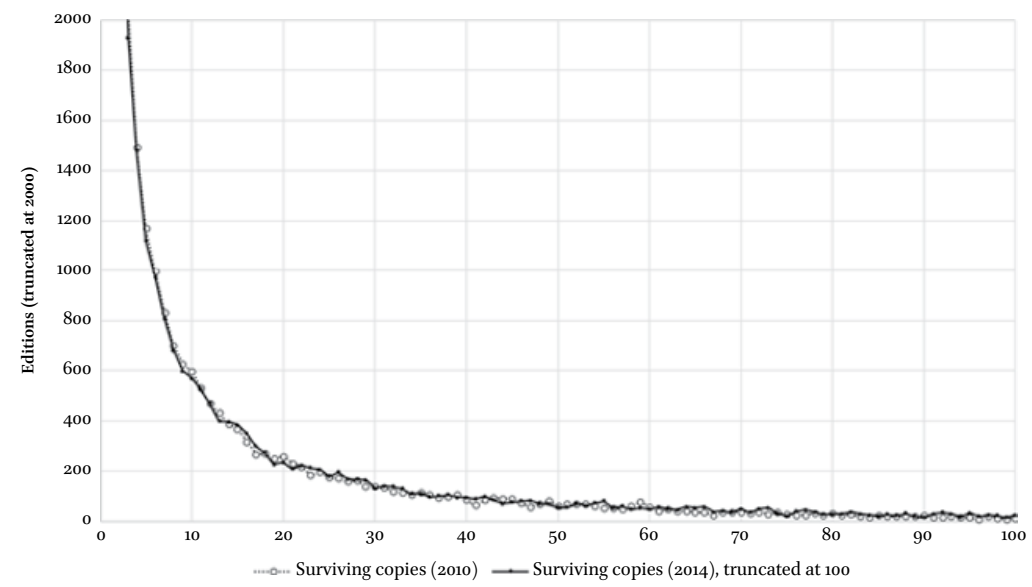

FIGURE 3.1 Consentius's curve of incunable preservation

3 Bradley Efron and Ronald Thisted, 'Estimating the Number of Unseen Species: How Many Words Did Shakespeare Know?', Biometrika, 63 (1976), pp. 435-447; A.J. Stam, 'Statistical Problems in Ancient Numismatics', Statistica Neerlandica, 41 (1987), pp. 151-174.

4 Ernst Consentius, 'Die Typen und der Gesamtkatalog der Wiegendrucke. Eine Kritik', Gutenberg-Jahrbuch, 7 (1932), pp. 55-109, here p. 84: "Wieviel Inkunabeln sind z.B. in sieben Exemplaren vorhanden, in sechs Exemplaren usw. bis herunter zu der Unsumme von Inkunabeln, die nur in einem Exemplar bekannt sind. Diese Zahlen, in eine graphische Tabelle eingezeichnet, ergeben eine Kurve, deren Verlauf für die Frage: Was ist uns verloren? Aufschluß geben dürfte." 
Scholars of early printing have been slow to recognize both what the graph proposed by Consentius would look like, and its troubling implications. One can find estimates that as few as five percent of incunable editions have entirely disappeared even in relatively recent literature. ${ }^{5} \mathrm{~A}$ few scholars, however, including Paul Needham and Neil Harris, have pointed out that the number of editions known from one or a few copies suggests a much higher number of missing editions. ${ }^{6}$ Sketching out the graph proposed by Consentius was hindered for decades by delays in publishing comprehensive incunable censuses, while even the newest online databases make it no simple task to determine the number of known copies of each edition.

Attempts from the field of early printing to estimate the number of lost editions have proceeded largely independently of the massive statistical literature on the unseen species problem and the now well-established methods and tools that have followed from it. In a series of articles since 1993, Neil Harris has analyzed loss and survival of early printed editions in terms of exponential decay, assuming a constant ratio between editions recorded in some number of copies and the number of editions recorded in the next lower number of copies: in a hypothetical case, " 400 are recorded in a single copy, 240 in two, 144 in three, 86 in four, $5^{2}$ in five, and so on." With a constant ratio of 0.6 between them, one could then project that 667 editions (400 divided by 0.6 ) were entirely lost. ${ }^{7}$ Harris's method pointed to a higher number of missing editions in many situations than previously assumed, and represented a first step towards determining an estimate. But there is no obvious reason for the survival of early printed books to take the form of exponential decay, and it is now clear that this model does not fit the data for incunables. Quite apart from any statistical test of goodness of fit, no constant ratio can be found that fits the steep decline between 1- and 2-copy editions that can also account for the many incunable editions surviving in hundreds of copies. The curve of Consentius cannot be described as exponential decay.

An important step forward came with the publication in 2007 and 2008 of two articles by Goran Proot and Leo Egghe that applied probabilistic reasoning to estimating the number of Jesuit play programs printed in Flanders in the

5 See for example Uwe Neddermeyer, Von der Handschrift zum gedruckten Buch: Schriftlichkeit und Leseinteresse im Mittelalter und in der frühen Neuzeit. Quantitative und qualitative Aspekte (Wiesbaden: Harrassowitz, 1998), I. 120-121.

6 Paul Needham, 'The Late Use of Incunables and the Paths of Book Survival', Wolfenbütteler Notizen zur Buchgeschichte, 29 (2004), pp. 35-6o, here p. 36.

7 Neil Harris, 'Marin Sanudo, Forerunner of Melzi', La Bibliofilia, 95-96 (1993-94), pp. 1-37, 101-145, 15-42; here p. 12, n. 19. 
eighteenth century based on the number of surviving copies. ${ }^{8}$ Crucially, they show that the estimation of lost editions does not depend on knowing the total or average print runs as long as one can assume a print run of around $150 \mathrm{cop}-$ ies or more, a quite reasonable assumption for early printing. Proot and Egghe propose an equation based on the number of editions surviving in one and two copies to establish a point estimate of the number of missing editions. Their method depends on the assumption that copies survive independently of each other: that is, the survival or loss of one copy does not affect the survival or loss of another copy. One could argue that this is true of the Jesuit play programs they took as their data set, but it is a point that has been vigorously opposed by Joseph Dane and may not be tenable for more diverse material. ${ }^{9}$

The next step forward came with Quentin Burrell's response to Proot and Egghe's paper in 2008.10 Burrell observed that Proot and Egghe's approach involves the assumption that print runs and survival rates are similar for each edition, which is again plausible for play programs (but may not be true of other genres and is certainly not true of incunables as a whole). Burrell showed that cases like the Jesuit play programs described by Proot and Egghe, where the print run is high and the likelihood that any copy will survive is low, represent a particular case of the unseen species problem, and that the number of lost play programs could be estimated using established statistical methods. ${ }^{11}$ Burrell was able to demonstrate that the binomial distribution used by Proot and Egghe was consistent with their data, but could also be described as a special case of another type of distribution, the Poisson distribution. With this insight, Burrell was able to establish a confidence interval for the number of original editions. Rather than the values put forward as precise estimates by Proot and Egghe - 3,903 original editions with 3,099 now lost - Burrell showed

8 Leo Egghe and Goran Proot, 'The Estimation of the Number of Lost Multi-copy Documents: A New Type of Informetrics Theory', Journal of Informetrics, 1 (2007), pp. 257-268; Goran Proot and Leo Egghe, 'Estimating Editions on the Basis of Survivals: Printed Programmes of Jesuit Plays in the Provincia Flandro-Belgica before 1773, with a Note on the "Book Historical Law", Papers of the Bibliographical Society of America, 102 (2008), pp. 149-174.

9 Joseph A. Dane and Rosemary A. Roberts, 'The Calculus of Calculus: W.W. Greg and the Mathematics of Everyman Editions', Studies in Bibliography, 53 (2000), pp. 117-128.

10 Quentin L. Burrell, 'Some Comments on "The Estimation of Lost Multi-copy Documents: A New Type of Informetrics Theory" by Egghe and Proot', Journal of Informetrics, 2 (2008), pp. 101-105.

11 Burrell, 'Some Comments', p. 102: "In what follows we assume that, for each document, $n$ is large and $\theta$ is small”; "We need to make the assumption, implicit in [Egghe and Proot], that $\lambda=n \theta$ is similar for each document." 
that the range of possible values lay (with 95\% certainty) between 3,165 and 4,442 original editions, of which the range of lost editions lay between 2,361 and 3,638 .

Our article, published with Paul Needham in 2010, represented a first attempt to apply current statistical methods to the problem of lost incunable editions. ${ }^{12}$ Our approach began with the recognition that the curve proposed by Consentius could be described as a statistical distribution. We proposed a negative binomial distribution as the best fit for the data. Although not seen in popular literature and journalism as often as the bell curve of the normal distribution, negative binomial distributions are common in statistical work. Already in 1943, Fisher used a negative binomial distribution to address the unseen species problem posed by Malaysian butterflies. A negative binomial distribution can be thought of as a distribution composed of many different Poisson distributions, each of which models the chance of an event occurring a certain number of times. For our treatment of incunable survival, each Poisson sub-distribution models the process whereby some class of editions might survive, and the negative binomial distribution aggregates this information into an overall distribution for incunables.

A negative binomial distribution has the additional important quality that it can describe outcomes that are correlated rather than independent. This is a significant advantage, as any historically coherent account of book loss or survival has to take into account that books are not preserved or destroyed independently of each other. Most obviously, books are collected together in the same binding or in the same library, and when one goes up in flames the chances become very high that others will as well. What is not as obvious is that the decision to discard an old book is not independent of the same decision reached by another owner: when one person observes another's discarding of a book as unfashionable or outdated or heretical, it affects the first person's choice about whether to keep or discard their copy. Inasmuch as book owners influenced each other's decisions to discard books, their decisions were not entirely independent. Alternately, a book may be deemed less important by many different owners acting independently, but all of them expressing correlated tastes or preferences. Statistical arguments about incunable survival require a distribution such as a negative binomial that tolerates dependence across observations.

\footnotetext{
12 Jonathan Green, Frank McIntyre and Paul Needham, "The Shape of Incunable Survival and Statistical Estimation of Lost Editions', Papers of the Bibliographical Society of America, 105 (2011), pp. 141-175.
} 
Our next step was to apply another standard tool of contemporary statistics that also has its origins in the work of Ronald Fisher: the maximum likelihood estimation. Most statistical distributions can be characterized by one or a few parameters. The bell curve of the normal distribution, for example, can be entirely defined by its mean - the peak of the curve - and by its standard deviation. If one has a data set, such as physical measurements or survey results, that conform to a normal distribution (and there are reliable ways to determine if they do), then one can discover which values for the arithmetic mean and the standard deviation define the bell curve that best fits the collected data. The equations for finding the optimal values for these parameters that yield the best fit with the known data - the maximum likelihood estimation are already well known for most distributions, including the negative binomial distribution, although their solutions may require the use of computational methods rather than simply 'solving for $x$ ' familiar from secondary school level algebra. By establishing the parameters that yield the best fit for the existing data, one receives in return a distribution that includes projections for those areas where the data are missing and thus the most likely estimate of the missing data. By determining the parameters of a negative binomial distribution that best fit the data for incunable editions surviving in one to more than 1,200 copies, one can predict the probable number of missing editions surviving in zero copies. Our 2010 article found that the initial estimated loss rates for incunables were implausibly high; a continuing challenge of determining a maximum likelihood estimation for incunables is that Consentius's curve points sharply upward. As a recourse we limited the projection by introducing some reasonable assumptions about how many editions a single printer could publish over the span of a career.

Since 2010, the ISTC has expanded to include more incunable editions and additional copies, particularly from Austrian libraries. These new records have not changed the curve of Consentius significantly, but they have contributed to establishing a more tractable estimate. Table 3.1 summarizes the current data on how many copies are known of each incunable edition, which we use to determine a maximum likelihood estimation for a negative binomial distribution. The first column on the left shows the number of existing copies of each format known to the ISTC. The next column shows the fraction of those editions that are known from only a single copy, while the next column provides the result of a maximum likelihood estimation for the number of editions with zero copies. This number can be added to the number of known editions, yielding an estimate of the total number of editions and the estimated loss rate. The result is around 42,500 total editions printed in the fifteenth century, compared to the 29,000-odd editions known to the ISTC today, and a loss rate 


\begin{tabular}{|c|c|c|c|c|c|c|c|}
\hline \multirow[t]{2}{*}{ Format } & \multirow{2}{*}{$\begin{array}{l}\text { Existing } \\
\text { editions }\end{array}$} & \multirow{2}{*}{$\begin{array}{l}\text { Fraction with } \\
\text { one copy }\end{array}$} & \multirow{2}{*}{$\begin{array}{l}\text { Estimated } \\
\text { number with } \\
\text { zero copies }\end{array}$} & \multirow{2}{*}{$\begin{array}{l}\text { Estimated } \\
\text { number } \\
\text { printed }\end{array}$} & \multicolumn{3}{|c|}{ Estimated loss rate } \\
\hline & & & & & $\begin{array}{l}\text { Lower } \\
\text { bound }\end{array}$ & Mean & $\begin{array}{l}\text { Upper } \\
\text { bound }\end{array}$ \\
\hline Folio & 7927 & 0.06 & 1433 & 9360 & 0.14 & 0.15 & 0.16 \\
\hline Quarto & 13312 & 0.23 & 5354 & 18666 & 0.27 & 0.29 & 0.30 \\
\hline Octavo & 5092 & 0.45 & $343^{8}$ & $853^{\circ}$ & 0.38 & 0.40 & 0.43 \\
\hline Broadside & $235^{6}$ & o.6o & 3594 & $595^{\circ}$ & $0.5^{8}$ & 0.60 & 0.63 \\
\hline SUM & 28687 & 0.24 & 13819 & 42506 & 0.30 & 0.31 & 0.32 \\
\hline
\end{tabular}

of around $31 \%$, with a narrow range between the lower and upper bounds at 30 and $33 \%$ (although we will soon complicate this projection somewhat).

The method outlined here is the approach that has been suggested by modern statistics for over seventy years, and the approach that should be used for estimating the number of missing incunable editions and in similar problems in early printing. In general terms, the necessary steps for this approach entail the following:

1. Gathering data for the number of copies that exist of each relevant edition (in sufficient number in order to avoid unreliable results), and counting how many editions survive in a given number of copies.

2. Identifying a distribution, suitably truncated to account for the fact that missing editions are not seen, and applying the appropriate statistical tests to show that the distribution is a good fit for the data in question. ${ }^{13}$

3. Using the maximum likelihood estimation for the proposed distribution to find the parameters that yield the best fit for the data.

4. Applying these parameters to extend the truncated distribution to include zero in order to estimate the number of missing copies and find the confidence interval for the estimation.

13 Without this step, the formula described by Proot and Egghe, 'Estimating Editions', p. 163 cannot be applied to any other data set. For data sets that can be shown to fit the Poisson distribution underlying the work of Proot and Egghe, Burrell, 'Some Comments', 104-105 urges researchers to "adopt this more robust approach" that he outlines in his response. 
We discuss our statistical methods in greater detail in the appendix. While there are no alternatives to the general approach described above, our implementation of it is not unassailable. One could argue, for example, that another distribution would be more appropriate than the negative binomial distribution that we use. Even more crucially, how we arrive at an estimate depends not only on having enough data, but also on how we include or exclude data from our distribution. It is still necessary for book historians to determine how copies are to be assigned to different editions and how editions should be grouped together in particular categories. Even the most advanced application of statistical methods still requires scholars to make decisions based on historical evidence about how early printed books survived or were lost.

For example, one question that book historians will have to answer for themselves is if there is a single phenomenon known as 'incunable survival.' Certainly there is today: the vast majority of incunables reside in libraries and museums, and copies or editions are lost only when something extraordinary and terrible happens. But for the fifteenth and sixteenth centuries, 'incunable survival' must mean multiple things depending on the kind of book one has in mind. A handful of broadsides (that may have been used as printer's waste in book bindings) may not be directly comparable to a legal reference work (that was transferred in orderly fashion from one institutional owner to the next up to the present day). If we combine them together in a single estimate of incunable survival, then the number of surviving broadsides will affect how we estimate the number of surviving folio editions, and the number of surviving folios will affect how we estimate the number of surviving broadsides. Perhaps we want that to be the case, but perhaps we do not. The decision is not trivial, and there are significant consequences for our estimate.

We might decide, for example, that the format of an incunable, whether broadside, octavo, quarto, or folio, although a rough and imperfect categorization, nevertheless tells us something important about the kind of life a book was supposed to lead. We might therefore assume that the use and survival of an octavo, quarto, folio, and broadside (not to mention the rarer or more exotic formats) were different enough from each other that we should derive an independent estimate for each format that is not influenced by the surviving editions of other formats. Certainly the variations in surviving copies according to format suggest that we should take that possibility seriously (see fig. 3.2). If we derive separate estimates for each format, then we find that we estimate fewer lost folio editions, but quite a few more quartos, and many more missing octavos, while the data for broadsides does not permit any sensible estimate. The estimation does not fail for broadsides, but rather is entirely imprecise, to the point that we cannot reject any reasonable hypothesis or even many unreasonable 


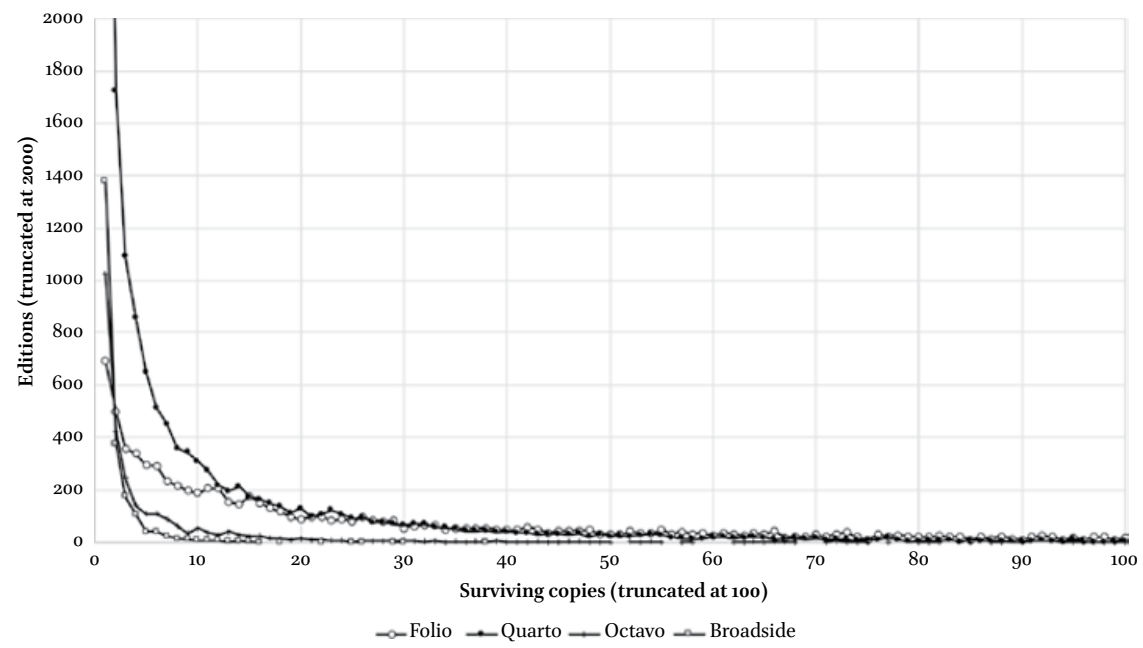

FIGURE 3.2 Surviving editions by incunable format

hypotheses. By combining these separate projections, we can then estimate the total loss rate (excluding a probably large number of broadsides) as having a lower bound of $49 \%$ and a mean projection of $62 \%$, while the upper bound becomes difficult to limit, largely due to the octavos (see table 3.2).

There is some reason to think that this second approach, using separate estimates based on format (while treating the higher estimates for octavos with some caution), is preferable. Initial analysis of other factors such as language, region, or year of production suggests that no other variable seems to affect survival as much as format does. While a book's physical size is a product of both its format and the number of leaves it contains, the format has a far greater effect than the leaf count on incunable survival. Books with more leaves usually tend to survive better, but doubling the number of leaves in a quarto does not make it behave like a folio in terms of its estimated loss rate, and doubling the number of leaves in an octavo does not make it behave like a quarto (see fig. 3.3). While the size and the number of leaves in a printed book are both factors in the book's bulk, they are distinct variables in what owners expected from their books and how they treated them.

And yet if the physical form of a book has implications for its expected use, one might reasonably wonder if the survival patterns differ not just between formats but also according to whether a book was comprised of few, several, or many leaves, and attempt to derive separate estimates for each segment. Table 3.3 displays the results of this analysis. For folios, the results are little changed, while the number of missing quartos rises significantly. For octavos, 
TABLE 3.2 Incunable loss rate estimated separately by format

Incunable format Lower bound Mean Upper bound

\begin{tabular}{llll}
\hline Folio & 0.07 & $\mathbf{0 . 0 8}$ & 0.08 \\
Quarto & 0.48 & $\mathbf{0 . 5 0}$ & 0.53 \\
Octavo & 0.80 & $\mathbf{0 . 9 1}$ & 0.99 \\
Total & 0.49 & $\mathbf{0 . 6 2}$ & 0.95 \\
\hline
\end{tabular}

Note: Estimating Broadsides by themselves did not yield any useful information, as the estimates were extremely imprecise.

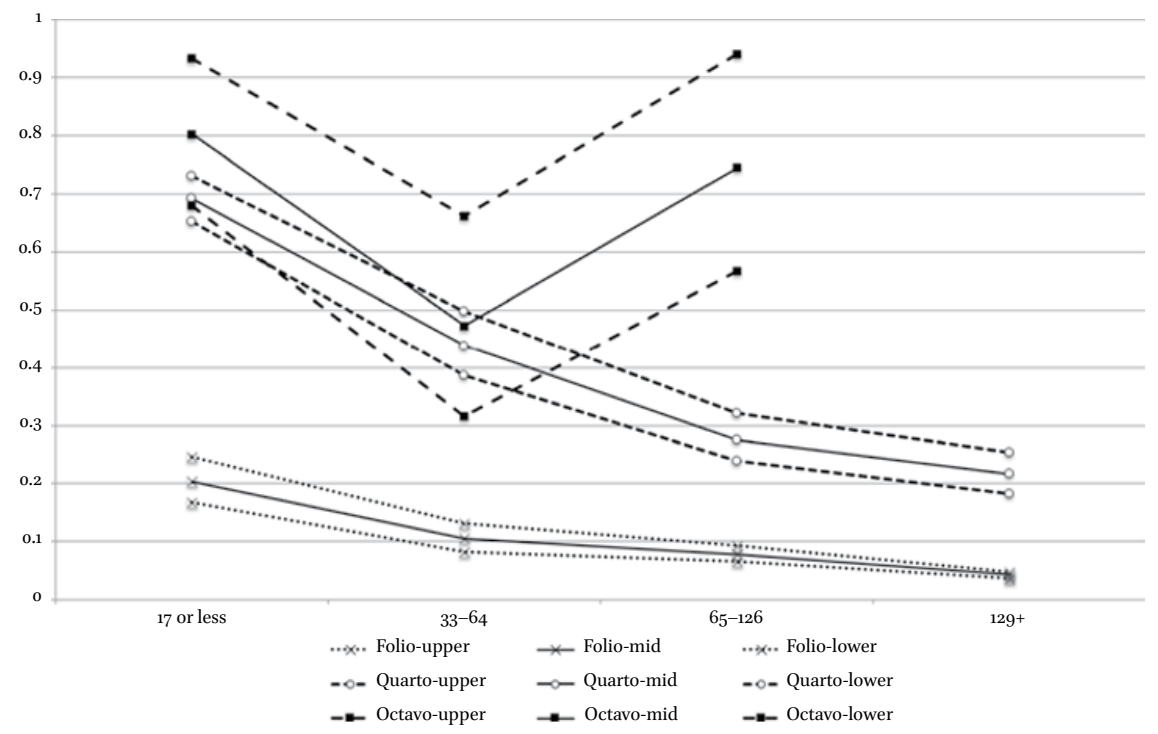

FIGURE 3.3 Incunable loss rate by size and leaf count

the smaller sample sizes allow only estimates with relatively high degrees of uncertainty or do not yield an estimate.

Using this approach, we might cautiously estimate the overall loss rate as around $63 \%$ of non-broadsides, just above our previous estimate, but the confidence interval is much broader - the upper bound is only limited by the assumption that none of the octavo categories have a loss rate higher than $95 \%$. These three figures $-31 \%$ of all incunables, and 62 or $63 \%$ of nonbroadsides - are not necessarily lower and upper bounds, but they are useful guideposts in our discussion. These estimates are in line with what we found in 2010 and still significantly higher than most prior estimates. 
TAB LE 3.3 Incunable loss rate by size and leaf count

\begin{tabular}{|c|c|c|c|c|c|}
\hline \multicolumn{2}{|c|}{ Incunable format } & \multirow{2}{*}{$\begin{array}{r}1-3^{2} \\
0.25\end{array}$} & \multirow{2}{*}{$\begin{array}{l}33-64 \\
0.13\end{array}$} & \multirow{2}{*}{$\begin{array}{l}65^{-128} \\
0.09\end{array}$} & \multirow{2}{*}{$\begin{array}{l}129^{+} \\
0.05\end{array}$} \\
\hline & Upper interval & & & & \\
\hline \multirow[t]{3}{*}{ Folio } & Mean & 0.20 & 0.11 & 0.08 & 0.04 \\
\hline & Lower interval & 0.17 & 0.08 & 0.07 & 0.04 \\
\hline & Upper interval & 0.73 & 0.50 & 0.32 & 0.25 \\
\hline \multirow[t]{3}{*}{ Quarto } & Mean & 0.69 & 0.44 & 0.28 & 0.22 \\
\hline & Lower interval & 0.65 & 0.39 & 0.24 & 0.18 \\
\hline & Upper interval & 0.93 & 0.66 & 0.94 & $*$ \\
\hline \multirow[t]{2}{*}{ Octavo } & Mean & 0.80 & 0.47 & 0.74 & $>0.95$ \\
\hline & Lower interval & 0.68 & 0.32 & 0.57 & $*$ \\
\hline
\end{tabular}

Total Calculated Loss Rate $=0.63$

\footnotetext{
Note. For octavos, loss rate estimates for editions with greater than 128 leaves are unavailable.

Total calculated loss rate is based on the assumption that no category suffers greater than 0.95 loss rate.
}

One might object that surviving incunables recorded in ISTC are not necessarily a representative sample of all books printed in the fifteenth century, but the objection is not quite on target. The statistical methods used here are not those of voter surveys, where one hopes that the mean response of the surveyed group is similar to the mean response of all voters. Of course the editions recorded by the ISTC are in some sense more likely to survive: they survived, and the others did not. But the advantage of using a negative binomial distribution is that it assumes that each edition has its own survival probability, and using a truncated distribution takes into account editions whose rate of survival is zero. As the method described here accounts for the truncation, the impact of having a sample skewed towards survival is minimized.

A more precisely differentiated estimate of missing editions helps us better understand fifteenth-century printing. When characterizing the careers of fifteenth-century printers, for example, we should take into account the size, format, and number of remaining copies of existing editions in order to gain an awareness of how much of the total output may be composed of the dark matter of missing editions. The exercise of thinking carefully about the data and applying current statistical methods to the problem of missing editions also allows us to make some useful observations about the lost books of various 
times and places. Preliminary analysis suggests that of all the major fifteenthcentury printing regions, France has the highest loss rates. One must remember, however, that 'loss' in this context means 'failure to become visible to ISTC as of yet', for which the physical destruction of all copies is only one possible cause. The slow rate of incorporation of the French regional incunable survey is another explanation, so that one may yet hope for the discovery of more editions from fifteenth-century French printers in collections off the beaten path.

The method employed here should be more broadly applicable to other centuries, although none of the databases of early printing for any region or century currently provide straightforward copy counts, and only a few (the Gesamtkatalog der Wiegendrucke and VD16, for sixteenth-century German printing) provide a leaf count or something resembling one. In the one case we can compare, which is German printing of the fifteenth and sixteenth centuries excluding broadsides, tentative analysis suggests a somewhat higher loss rate in the sixteenth century, with the lowest loss rate for German sixteenthcentury printing apparently found in the $15^{20}$ s, suggesting a durable interest in collecting and preserving works of the early Reformation. One must however be aware of the potential limitations of VD16 as a data source. Drawing on VD16 invites the objection (raised at our conference by Andrew Pettegree and Malcolm Walsby) that VDi6's census of copies is incomplete, that it lacks information about holdings outside of German-speaking Europe, and that it overlooks editions intended for export to other countries.

While all of these are valid concerns for book historians, they do not represent serious challenges to the approach described above for the statistical estimation of lost editions. Let us return to the island of the butterflies. We wish to estimate how many total species live on the island, but we are only able to survey a limited area. The relative prevalence of butterfly species on the island is of course interesting information for a lepidopterist, but our survey makes no claims about it; for that, a different sampling methodology and different type of statistical analysis would be required. That our survey overlooks many species, or that the surveyed area does not include the whole island, is not just unsurprising: it is precisely the point of the exercise. An increasingly complete survey may result in a more precise estimate, even as the estimate remains within the original range.

For sixteenth-century German printing, the survey plot comprises those libraries that provide data to VD16. For the book historian and bibliographer, our goal is naturally to have a record of every extant copy. But that is not a requirement for a statistically valid estimation of the number of editions unrecorded in VD16. The number of copies and editions suggest that the database 
records only a fraction of sixteenth-century German printing, but one must not forget that the unseen portion includes both editions that have been irretrievably lost, and editions that have not yet been recorded. That there are libraries and archives whose holdings of sixteenth-century German printing are yet to be incorporated into VD16, and that the database has only recently begun to include German-language editions printed abroad, are grounds for hope of discoveries yet to be made. As more editions come to light, we can expect a more accurate and likely larger estimate of the number of original editions. The database also omits some copies of well-represented items, but this may have only a minor effect on the confidence interval of the estimate of lost sixteenth-century German editions; Ronald Fisher's work with butterflies stopped counting specimens for each species when it reached 25 individuals.

What might make one hesitant about making pronouncements about sixteenth-century German printing based on VD16, however, are the types of material it excludes, as the database ignores broadsides, maps, and music notation. While VD16 includes Latin works printed in the core German-language area, early modern linguistic borders were complex and defy simple definition today. ${ }^{14}$ These editions are certainly relevant according to many definitions of sixteenth-century German printing, but VD16 banishes them from its island, so to speak, or swats them away like a lepidopterist might treat a mosquito. Yet for all its shortcomings, VD16 remains the best source of data (as opposed to mere information) about German printing in the sixteenth century. VD16 excels all other bibliographic databases in consistently formatting its data, making its full records easily accessible, and clearly distinguishing multiple copies held by single libraries. It may yet be eclipsed in completeness or accessibility by some other database, but that moment has not yet come. It is already clear, however, that applying any statistical technique to other segments of early printing requires careful consideration of a database's history and limitations, and that progress depends on bibliographic censuses' commitment to clarity, accuracy, and accessibility.

Neil Harris has raised the objection that miscellanies, compilations of multiple pamphlets as a single bound volume, should be eliminated from the count of surviving copies because the survival of an item in a miscellany was due only to its association with some other edition and not to any intrinsic

14 On the problematic borders of VD16, see Jürgen Beyer, 'How Complete are the German National Bibliographies for the Sixteenth and Seventeenth Centuries (VD16 and VD17)?', in Malcolm Walsby and Graeme Kemp (eds.), The Book Triumphant: Print in Transition in the Sixteenth and Seventeenth Centuries (Leiden: Brill, 2011), pp. 57-77. 
quality of the item itself. ${ }^{15}$ But the path by which a particular book survived into the present is partially or entirely unknown for most surviving incunables, so that there is no way to know for certain which pamphlets were at one time part of a miscellany and which were not. In addition, the particular path of survival plays no role in the statistical analysis presented here. Many and perhaps most quarto pamphlets are preserved in miscellanies or show signs of having been bound in such a volume at one time; it would be a mistake to eliminate from consideration those pamphlets that were preserved in the primary way that most pamphlets were preserved. It is true, however, that more study is needed of miscellanies and other paths of book survival, both as individual objects and as conglomerates, so that we can better characterize them using statistical or computational methods and improve our understanding of how books were preserved over the centuries. As noted above, deciding whether incunable survival is one thing or many things has significant consequences for estimating the number of lost editions.

Finally, where does this leave the curve of Consentius? As the incunable censuses and databases of early printing progress towards a comprehensive record of attested editions and extant copies, there are reasons to be cautiously optimistic that estimates of the character and number of lost incunable editions will stabilize. There are of course hypothetical cases where the discovery of new editions or copies of known editions in significant numbers would require a substantial revision of the number of lost editions. As the estimate of lost editions is most strongly affected by the ratio of 1-copy editions to the 2- and 3-copy editions, the discovery of many new 1-copy editions would create an even larger initial spike in the graph of editions known from a single copy, which would increase the estimate of the number of missing editions. And the discovery of many more second, third, and fourth copies of editions now known only by a single copy would decrease the ratio of 1-copy editions to other editions, leading to a lower estimate of missing editions.

But the cataloging efforts of the last several years have not brought about either of these outcomes. The ISTC now records over 75,000 more copies than it did in 2010, bringing the total number of copies known to it close to 500,000. Some of these newly added copies represent previously unknown editions, but most are additional copies of already well-known works. There are now only 2,400 more copies recorded of the more than 25,000 editions known in as many as 30 copies, while the 4,400 editions known in $31-150$ copies grew by over 50,000 copies since 2010 . Consequently the ratio of 1-copy editions to 2- or

15 Neil Harris, 'Statistiche e sopravvivenze di antichi romanzi di cavalleria', in Michelangelo Picone and Luisa Rubini (eds.), Il cantare italiano fra folklore e letteratura (Florence: Olschki, 2007), pp. 383-412, here pp. 399-400. 
3-copy editions has remained virtually unchanged. On the basis of the new records, the lowest current projection of missing editions is now somewhat lower than the lower bound we estimated in 2010, and the estimation of confidence intervals has become more tractable. ${ }^{16}$ We can look forward to more progress of this kind in the future as more copies and new editions are recorded, hopefully bringing more precision to estimates involving small quartos or octavos. The poor preservation of broadsides, however, may leave anything more than an impressionistic guess about their loss rates forever out of reach.

\section{Statistical Appendix}

Here we describe in more detail the statistical methods we used for the results discussed in the text. Our approach uses a negative binomial regression to model book survival, with the distribution truncated at zero to recognize that lost editions with zero copies were not observed. Once we estimated the parameters of this model based on the observable data, we calculated the probability that an edition would have zero observations, which was what we needed in order to estimate the number of missing editions. ${ }^{17}$

We provide several estimates of missing editions in the text, each resulting from successively relaxing the constraints on the data. Our first estimate involved a maximum likelihood estimate of a truncated negative binomial model where we included the following terms as mean shifters, comparable to regressors in a standard regression, or in other words, the factors that affect the survival rates we wish to analyze:

1. Dummy variables (in statistical parlance, a variable that represents not a numerical quantity but rather a yes-no condition such as quarto or nonquarto, octavo or non-octavo) for each of the formats smaller than folio to allow for baseline differences across formats.

2. A quartic polynomial function to model the influence of leaf count on survival, with different estimates of the coefficients for each multi-leaf format (folio, quarto, and octavo). ${ }^{18}$

16 Cf. Green, McIntyre and Needham, 'The Shape of Incunable Survival', p. 169.

17 The STATA statistical software includes built-in functions for truncated negative binomial maximum likelihood models, which are easily run once the data has been prepared and cleaned.

18 If $L_{i}$ represents the number of leaves in some folio edition $i$, then the polynomial equation would be $\alpha_{1}^{\text {folio }} L_{i}+\alpha_{2}^{\text {folio }} L_{i}^{2}+\alpha_{3}^{\text {folio }} L_{i}^{3}+\alpha_{4}^{\text {folio }} L_{i}^{4}$. We estimate different coefficients $a_{1}-a_{4}$ for octavos and quartos. 
3. Dummy variables for the regions beyond Italy where the works were published: Bohemia, England, France, Germany, Netherlands, Spain, and other. Thus Italy is the baseline.

4. Dummy variables for the decades from 1460 to 1490.

5. Dummy variables for languages besides Latin: German, French, Italian, and other.

In this first pass, table 3.4 gives the results in full for the estimation.

The largest concern is that the negative binomial distribution may have a different shape for the different formats such that the same parameters will not fit both a set of broadsides and folios, for example. Thus we rerun the above regression separately for the four different formats. This regression still includes all the variables mentioned above, with appropriate modifications

TABLE 3.4 Incunable loss rate regression results

\begin{tabular}{lcl}
\hline Total & Coefficient & Standard error \\
\hline $\log$ Leaves & -0.09 & 0.36 \\
$\log$ Leaves squared & 0.34 & 0.16 \\
$\log$ Leaves cubed & -0.07 & 0.03 \\
$\log$ Leaves quartic & 0.00 & 0.00
\end{tabular}

Quarto interaction

$\begin{array}{lrl}\log \text { Leaves } & 0.54 & 0.49 \\ \log \text { Leaves squared } & -0.50 & 0.23 \\ \log \text { Leaves cubed } & 0.12 & 0.04 \\ \log \text { Leaves quartic } & -0.01 & 0.00\end{array}$

Octavo interaction

$\begin{array}{lrl}\log \text { Leaves } & -1.96 & 1.34 \\ \log \text { Leaves squared } & 1.01 & 0.58 \\ \log \text { Leaves cubed } & -0.17 & 0.11 \\ \log \text { Leaves quartic } & 0.01 & 0.01\end{array}$

Format (baseline Folio)

$\begin{array}{lll}\text { Broadsides } & -0.82 & 0.30 \\ \text { Quarto } & -0.08 & 0.38 \\ \text { Octavo } & -0.31 & 1.09\end{array}$




\begin{tabular}{lll}
\hline Total & Coefficient & Standard error \\
\hline Region (baseline Italy) & & \\
Bohemia & -1.09 & 0.20 \\
England & -1.21 & 0.08 \\
France & -1.32 & 0.03 \\
Germany & 0.07 & 0.02 \\
Netherlands & -1.10 & 0.04 \\
Spain & -1.74 & 0.06 \\
Other & -1.26 & 0.15 \\
Decade (baseline 1450's) & & \\
1460 & -1.31 & 0.29 \\
1470 & -1.18 & 0.27 \\
1480 & -1.05 & 0.27 \\
1490 & -0.93 & 0.27 \\
Language (baseline Latin) & & \\
German & -1.22 & 0.03 \\
Italian & -1.07 & 0.03 \\
French & -1.55 & 0.05 \\
Other & -0.68 & 0.05 \\
Constant & 2.55 & 0.40 \\
N = 25,878 & & \\
& & \\
\hline
\end{tabular}

(we do not, for example, include a dummy variable for octavos in the quarto regression). We do not provide all the underlying estimation results here, but the resulting loss rates and confidence intervals are reported in the text. Full estimation results are available from the authors.

Finally, we also allow for a very open optimization process where we estimate the model separately by number of leaves and format. For this approach to estimating survival rates, even with hundreds or thousands of editions in each category, it is in some cases difficult to make confident predictions and in some cases the estimation procedures fails to yield any useful information. We no longer need to include the flexible leaf count polynomial, so we replace it with a simple linear variable for the number of leaves. We also eliminate region (as it overlaps strongly with language) and restrict decade to a linear term rather than dummy variables. This simplification reduces the demands on the nonlinear optimization without doing too much violence to the estimation. 
Determining confidence intervals can be difficult for these nonlinear estimators. We used a bootstrapping technique which involved rerunning our estimation 500 times on a subsample of the observed data for each loss rate estimate in order to determine a confidence interval for the loss rate. When the results had difficulty converging, the bootstrap could fail. Furthermore, maximum likelihood estimation at boundaries is problematic, and this problem is not solved by bootstrapping, thus the confidence intervals for estimates near $100 \%$ loss are only tentative.

For each of the observed editions, we estimate an expected loss rate. Once we have an expected loss rate for each observed edition, we then determine a weighted average of the loss rates, as found in the text above. The weighting is necessary to account for the fact that we want to know the loss rate for the latent population of all editions, including missing editions, but we only see the surviving editions. Thus one edition with an expected loss rate of $90 \%$ represents ten editions, including itself and nine others that have disappeared. An edition with an estimated loss rate of $50 \%$ would represent two editions, including one that has disappeared. ${ }^{19}$ The sum of all observed editions and the additional lost editions that each surviving edition represents is used to determine the average loss rate.

19 The appropriate weights are computed as $\frac{1}{1-\text { loss rate }}$. 